\title{
Physiology and metabolism of ectomycorrhizae
}

\author{
C. Bledsoe ${ }^{1}$, D. Brown 1 , M. Coleman 1 , W. Littke ${ }^{2}$, P. Rygiewicz ${ }^{3}$, \\ U. Sangwanit ${ }^{4}$, S. Rogers 5 and J. Ammirati ${ }^{5}$
}

1 College of Forest Resources AR-10, University of Washington, Seattle, WA 98195 U.S.A.

2 Weyerhaeuser Corp., Centralia WA, U.S.A.,

3 US EPA, Corvallis, OR, U.S.A.,

4 Forest Biology, Kasetsart University, Bangkok, Thailand, and

5 Botany Dept., University of Washington, Seattle, WA, U.S.A.

\section{Introduction}

Managed forests are the forests of today. In these forests, growth and yield are improved by forest fertilization. Application of fertilizers, often nitrogen, has created a need for more understanding of how mineral nutrients, roots and soils interact. This need has produced new partnerships among forest soil scientists, root physiologists, soil microbiologists, tree nutritionists and mycorrhizal research workers. The study of mycorrhizae is a critical interface in understanding the processes by which nutrients are transferred from the soil through fungal hyphae into roots, then metabolized and distributed throughout the tree. This interface between root and fungus is illustrated in Fig. 1.

The following is a discussion of ectomycorrhizal fungal physiology and its effects on coniferous trees, particularly effects on nutrient uptake, tree nutrition and water stress. This discussion focuses on 10 years of research conducted by our mycorrhizal group in forestry at the University of Washington. Our research program has focused on two central questions: How do ectomycorrhizal fungi affect processes of nutrient uptake by forest tree species? And, do fungal species differ in their abilities to affect physiological processes in general?

\section{Nutrient uptake and metabolism}

Inorganic nitrogen uptake

Inorganic ammonium and nitrate are assumed to be the major forms in which nitrogen is taken up by tree roots. Forest soils generally contain more ammonium than nitrate, although levels of either ion are relatively low. Although organic nitrogen is also an important form of nitrogen, more attention has been directed to inorganic forms. Soil pH is both affected by and affects uptake of ammonium and 


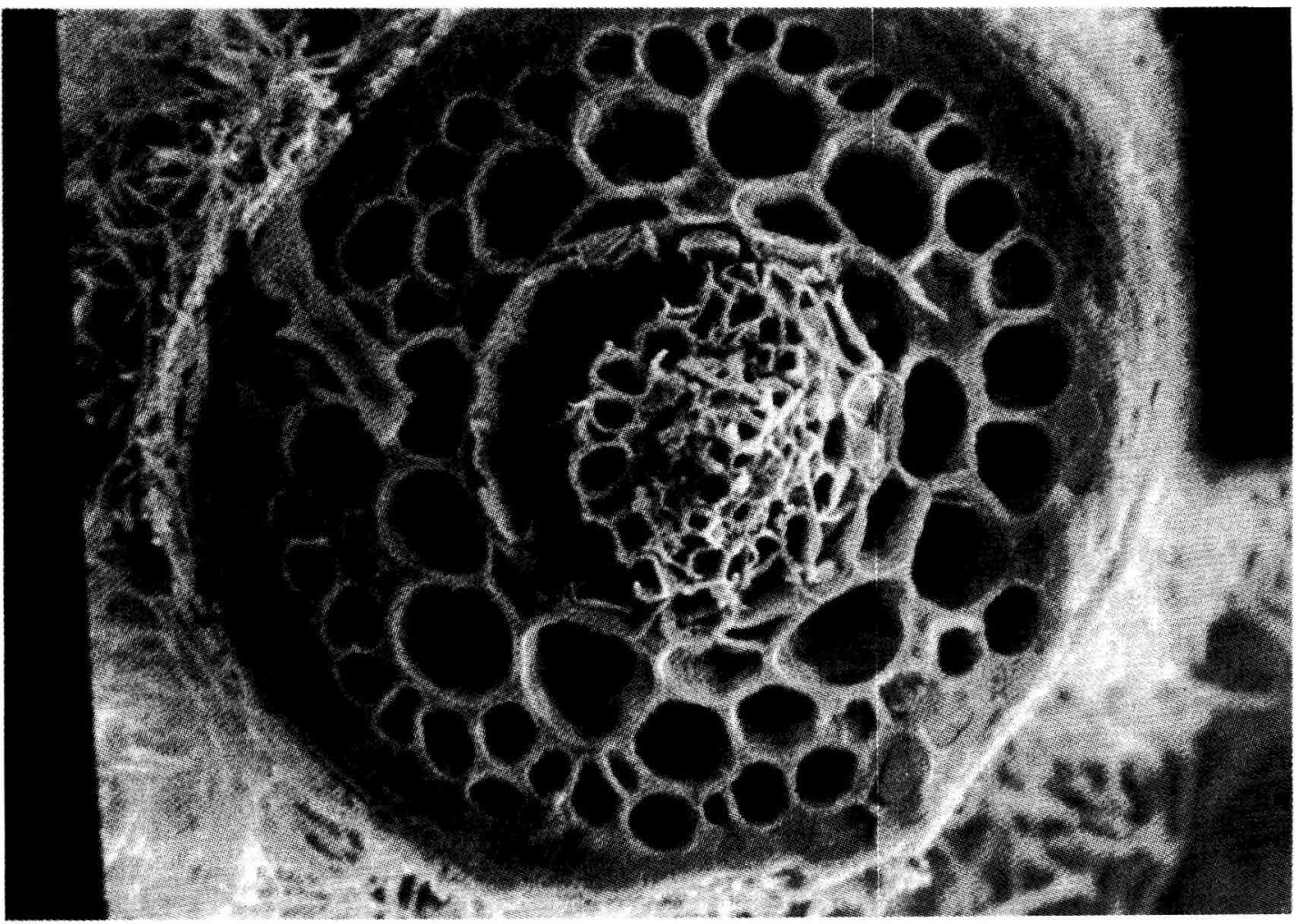

Fig. 1. Scanning electron micrograph, Douglas fir roots and Hebeloma crustuliniforme, $200 \times$ (photo: Kelly Leslie).

nitrate. With ammonium uptake, hydrogen ions are released into the rhizosphere, while uptake of nitrate results in hydroxyl ion release. These exchanges balance charge in the roots and substantially alter $\mathrm{pH}$ around the roots. This affects availability and uptake of many ions (particularly phosphorus).

In our lab, we measured uptake of ammonium and nitrate by 3 conifer species (Douglas fir, western hemlock and Sitka spruce) which were either nonmycorrhizal or mycorrhizal with Hebeloma crustuliniforme (Bull. ex. Fr.) Quel. (Rygiewicz et al., 1984a, b). Seedlings were grown in solid media, then transfer- red to solutions for short uptake periods. Uptake rates decreased with increasing acidity, so that rates at $\mathrm{pH} 3$ were only $50-70 \%$ of rates at $\mathrm{pH} 7$. Mycorrhizal plants generally had higher uptake rates over the entire $\mathrm{pH}$ range, particularly Douglas fir. Mycorrhizal effects were much more noticeable for ammonium uptake than for nitrate uptake. Unlike many crop species, uptake rates for ammonium were higher, about 10-fold, than nitrate uptake rates. Since ammonium levels in forest soils are generally higher than nitrate, higher uptake rates might be expected.

Mycorrhizal roots did not release as much $\mathrm{H}^{+}$per ammonium taken up as did 
non-mycorrhizal roots. This finding suggested that mycorrhizal fungi may buffer ammonium uptake, allowing uptake to continue at faster rates by reducing acidification in the rhizosphere. Another interesting observation was that ions were not only being taken up by roots, but were also being released - sometimes in substantial amounts. Potassium efflux was noted. Clearly, loss or efflux of ions must be a temporary phenomenon, since plants increase in size and nutrient content over time. Our results simply indicated that influx or efflux of a particular ion may change from time to time, depending upon conditions. We have shown cation efflux during a period of rapid ammonium uptake by Douglas fir roots (Cole and Bledsoe, 1976). When all the ammonium in the solution was depleted, cations were reabsorbed. Although it may seem inefficient, plant roots both take up and release ions at rapid rates. Some ions are certainly retained, but this may be a small percentage of the total flux.

\section{Potassium fluxes in roots}

Our interest in ionic fluxes into and out of roots led to a study of mycorrhizal effects on these fluxes. Using a compartmental analysis technique, we labeled Douglas fir roots for $24 \mathrm{~h}$ with radioactive rubidium (potassium tracer) (Rygiewicz and Bledsoe, 1984). After labeling, rubidium efflux was tracked for $10 \mathrm{~h}$. Mathematical analyses of efflux data allowed data to be separated into fluxes and pool sizes for 3 compartments: cell wall/free space, cytoplasm and vacuole.

There was rapid influx and efflux of potassium. About $95 \%$ of all potassium entering roots was subsequently released; net accumulation was only $5 \%$ of total flux. Mycorrhizal fungi did alter fluxes, with more storage of potassium in the vacuoles of mycorrhizal root cells. Half-lives of potassium in all 3 cellular compartments were increased by mycorrhizal fungi. For example, in the vacuolar compartment, the half-life was $25 \mathrm{~h}$ for mycorrhizal roots, but only $6.6 \mathrm{~h}$ for non-mycorrhizal roots. These data suggest that mycorrhizal fungi can alter ion fluxes through roots, reducing efflux and resulting in increased retention in the roots. Higher fungal metabolic rates may increase energy for active uptake and retention of ions.

\section{Cation-anion balance}

These mycorrhizal effects on ionic fluxes led us to ask whether mycorrhizal fungi can change total ionic flux into cells. A cation-anion balance sheet was determined for mycorrhizal and non-mycorrhizal Douglas fir seedling roots during a short uptake period (Bledsoe and Rygiewicz, 1986). Influx and efflux of cations (ammonium, potassium, calcium, $\mathrm{H}^{+}$) and anions (phosphate, sulfate, chloride and bicarbonate) were measured using stable and radioisotopes and chemical analyses.

In this experiment, mycorrhizae had little effect on total fluxes, but they did increase anion uptake and bicarbonate release. For all treatments, cation fluxes were much more rapid than were anion fluxes; 25 times more cations enter and leave root cells than anions. This massive cation influx was not balanced by parallel anion influx, but by efflux of $\mathrm{H}^{+}$and potassium. The very small amount of anion influx was balanced by bicarbonate efflux. Most cations were presumably stored in vacuoles as salts of organic acids. Our calculations suggest that both mycorrhizal and non-mycorrhizal coniferous roots synthesize large amounts of organic acids.

Using data from the literature, we compared our data on coniferous roots to those on several major crop species and 
Table I. Cation-anion fluxes in coniferous roots and in roots of herbaceous agricultural species (from Bledsoe and Rygiewicz, 1986).

\begin{tabular}{llllllll}
\hline & $\mathrm{NH}_{4}^{+}$ & $\mathrm{H}^{+}$ & $\mathrm{K}^{+}$ & $\begin{array}{l}\text { Other } \\
\text { cations }\end{array}$ & $\mathrm{HCO}-$ & $\begin{array}{l}\text { Other } \\
\text { anions }\end{array}$ & $\begin{array}{l}\text { Organic } \\
\text { acids }\end{array}$ \\
\hline Conifers & +5 & -27 & -8 & +22 & -1.3 & +0.03 & +21 \\
Crop spp. & +5 & -7 & nd & +2 & -1 & -1 & +1 \\
\hline
\end{tabular}

found a major difference. Coniferous roots take up cations at about twice the rate of herbaceous crop species -27 vs 14 microequivalents per gram dry wt. of roots per hour. Since hydrogen ions are the primary ion released to balance cation uptake, coniferous roots acidify the external medium (or soil) to a much greater extent than do roots of crop species. Conifer roots also synthesize greater quantities of organic acids than do crop species. Table I shows these fluxes.

\section{Organic nitrogen}

As indicated earlier, little attention has been paid to organic nitrogen uptake by plants or to fluxes and pool sizes of soluble organic nitrogen in forest soils. Early work by Melin in the 1950's demonstrated amino acid uptake by mycorrhizal roots. There have been few reports since then. We investigated uptake and utilization of organic nitrogen, since this pathway may be important for carbon and nitrogen assimilation by roots.

\section{Amino acid uptake}

Using 3 different amino acids, uptake rates by roots of Douglas fir and western hemlock were measured in solution culture (Sangwanit and Bledsoe, submitted; Bledsoe and Sangwanit, submitted). Seedlings were either non-mycorrhizal or mycorrhizal with Cenococcum geophilum Fr., H. crustuliniforme, or Suillus granulatus (L.: Fr) Kuntze. Net charge of these amino acids was either neutral (alanine), plus (aspartic acid) or minus (arginine) at $\mathrm{pH} 5.5$, the uptake solution $\mathrm{pH}$.

Uptake was measured by appearance in roots of $\left[{ }^{14} \mathrm{C}\right] \mathrm{amino}$ acids. The use of axenic seedlings precluded microbial degradation of the amino acids, which would have separated ${ }^{14} \mathrm{C}$ label from the amino acid. Ionic charge had little effect on rates, since they were similar - about $50 \mathrm{nmol}$ per $\mathrm{mg}$ of root per hour $\times 10^{-2}$ (Bledsoe and Sangwanit, submitted). The single exception was lower rates $(25 \mathrm{nmol})$ for arginine uptake by hemlock. Similarly, choice of host species had little effect on uptake rate, with the exception noted above for hemlock and arginine. Fungal effects were significant. Compared to nonmycorrhizal seedlings, rates for seedlings mycorrhizal with Hebeloma and Cenococcum were 25 and $33 \%$ higher, while rates for Suillus were lower - only $75 \%$ of the control rates. Thus choice of the fungal partner did affect amino acid uptake rates.

\section{Amino acid metabolism}

Metabolism of these 3 amino acids and a 4th amino acid, glycine, was affected both by type of amino acid and by mycorrhizae. After a $4 \mathrm{~h}$ uptake period, little glycine had been metabolized $190 \%$ unaltered glycine). In contrast, about $50 \%$ of the alanine was converted into non-amino carbon 


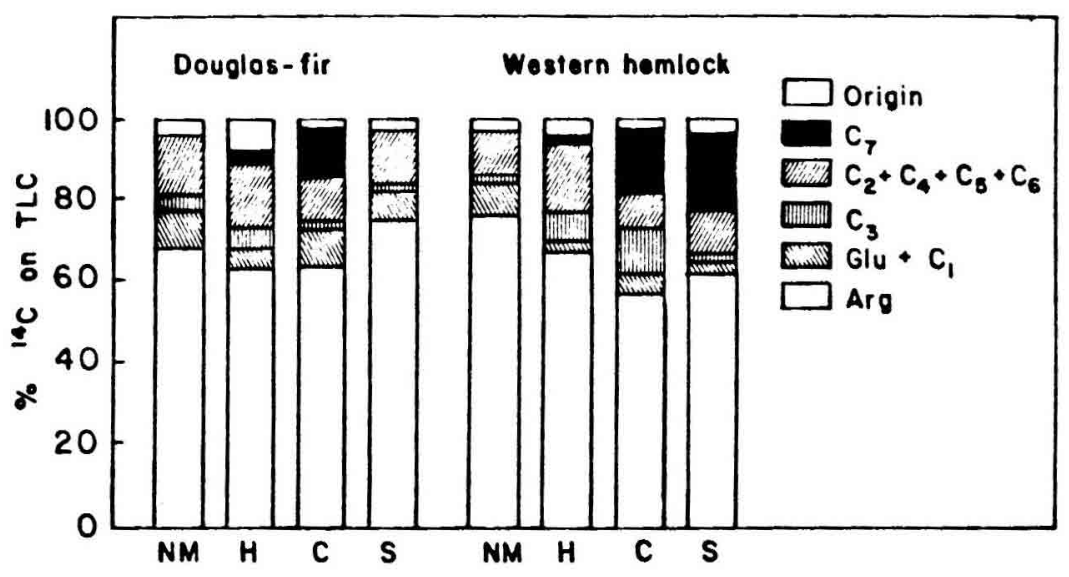

Fig. 2. Thin-layer chromatogram of conifer root extracts. Roots were labeled with $\left[{ }^{14} \mathrm{C}\right]$ arginine. (Bledsoe and Sangwanit, submitted).

compounds; less than $30 \%$ alanine remained. About 70 and $50 \%$ of arginine and aspartate, respectively, remained. When root extracts were chromatographed on thin-layer chromatograms, many ${ }^{14} \mathrm{C}$-labeled compounds were found. Mycorrhizal roots often contained ${ }^{14} \mathrm{C}$-label not found in non-mycorrhizal roots such as ' $\mathrm{C}_{7}$ ' in Fig. 2. This unknown compound was produced in 5 of the 6 mycorrhizal treatments, but not in non-mycorrhizal (NM) ones. These mycorrhizal-specific compounds were not identified.

\section{Amino acid transfer and storage}

Mycorrhizal roots might be expected to store amino acids in fungal tissues and to transfer less to the stele, in contrast to non-mycorrhizal roots. Using $\left[{ }^{14} \mathrm{C}\right]$ glycine (Sangwanit and Bledsoe, submitted), we found that non-mycorrhizal roots did transfer much of their glycine directly to the shoot, whereas mycorrhizal roots stored more glycine in the roots.
Using microautoradiography, the location of glycine in root tissues was determined (Sangwanit and Bledsoe, submitted). In a time series uptake experiment, mycorrhizal and non-mycorrhizal Douglas fir roots were exposed to glycine for 1,4 , 12 and $24 \mathrm{~h}$. Then root tips were frozen in liquid $\mathrm{N}_{2}$, freeze-dried at $-70^{\circ} \mathrm{C}$, and vacuum-embedded with a low viscosity, non-water soluble resin (to prevent movement of water-soluble glycine). After cutting ultramicrotome sections, root sections were covered with a film emulsion and stored. After photographic development, black dots on the film indicated $\left[{ }^{14} \mathrm{C}\right]$ glycine in root tissues.

Glycine appeared in the stele of nonmycorrhizal roots at $1 \mathrm{~h}$; transport continued throughout the $24 \mathrm{~h}$ experiment (Sangwanit and Bledsoe, submitted). For mycorrhizal roots, however, much of the glycine was stored in the fungal mantle. Gradually, glycine was transferred to the stele over the $24 \mathrm{~h}$ experiment. These results indicate that mycorrhizal roots can serve as a storage organ for organic nitro- 
gen in roots. Perhaps in a forest soil, organic nitrogen may be taken up directly by the fungi and stored in the mantle. At later times, these amino acids could be used as a source of both carbon and nitrogen for fungal growth as well as for root or tree growth.

\section{Fungal physiological diversity}

Our previous discussion has documented the beneficial effects of mycorrhizae on nutrient uptake and metabolism. These results led to the following question. Do fungal species differ in their abilities to affect physiological processes in general? For example, there are a large number of fungal species - more than 1000 - that may form mycorrhizae with Douglas fir (Trappe, personal communication). Why are there so many different fungi? Do they have different ecological niches? Do they carry out different functions in association with tree roots? This puzzling fungal diversity is the focus of our current work.

\section{Identification of fungi on roots}

Before studying fungal diversity, it is necessary to know whether diversity of fungal fruit bodies is related to mycorrhizal diversity. Are fungi which form fruit bodies also functioning mycorrhizae? We are studying fruiting patterns and mycorrhizal patterns on roots in the same field plots (Rogers, personal communication). If there are correlations between fruiting patterns and root-associated mycorrhizal fungi, then we can assume that taxonomic diversity is related to mycorrhizal diversity. In order to know which fungi are present on roots, it is necessary to identify root fungi. However, fungal taxonomy is based on characteristics of the fruit body. It is very difficult to characterize root-associated fungi based solely on color and culture characteristics (Bledsoe, 1987) and many mycorrhizal fungi have not been grown in culture.

We are developing an identification procedure based on rDNA patterns (Rogers et al., 1988). Using about $1-100 \mathrm{mg}$ from fruit bodies (fresh or dried), fresh-cultured fungal mycelia or mycorrhizal roots, rDNA was extracted using a CTAB micropreparation method (Fig. 3). After extraction and purification, the DNA was restricted with EcoRI, run on an agarose gel and Southern blots were made with a yeast pBD4 probe.

Fig. 4 shows an autoradiograph of rDNA blot-hybridization patterns from mycorrhizae of Rhizopogon vinicolor A.H. Sm: lane $1=$ mycelial culture only; lane $2=$ Douglas fir mycorrhizal roots; lane $3=$ uninfected roots. The position of fungal bands was separate from those of the conifer roots. Thus, the fungus infecting the root could be identified by comparison to patterns from a 'library' of mycorrhizal fungal patterns. Since fungal and root patterns did not overlap, it is not necessary to separate fungal and root tissues before DNA extraction - a considerable advantage.

\section{Fungal physiological diversity}

Although many fungi fruit in association with Douglas fir, little is known about which fungus is appropriate for any set of environmental conditions. We studied one aspect of physiological diversity - the ability of fungi to tolerate water stress (Coleman et al., 1988). Over 50 isolates were tested in pure culture, using polyethylene glycol to adjust medium water potential.

In response to stress, 3 different growth patterns were observed (Fig. 5). For type I, fungi were intolerant of stress and grew 


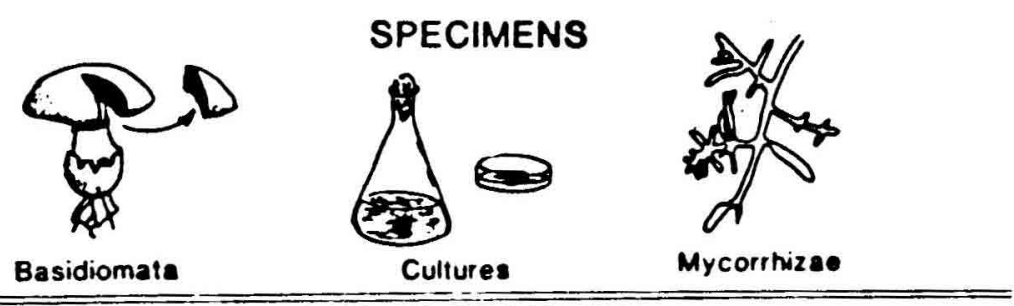

\section{DNA EXTRACTION}

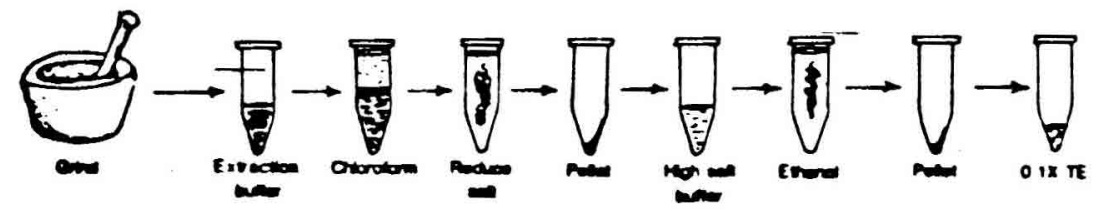

SOUTHERN HYBRIDIZATIONS

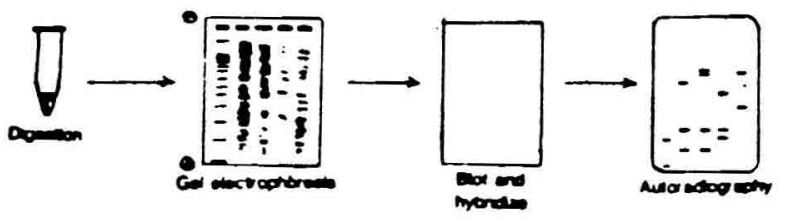

Fig. 3. Diagram of extraction procedure for rDNA (from Rogers et al., 1988).



only at the lowest level of stress $(-0.02$ $\mathrm{MPa}$ ). For type II, fungi did tolerate some stress. Growth rates decreased with increasing stress; maximum growth occurred in the lowest stress level. For type III, fungi were much more tolerant of stress and even grew faster at a moderate stress level. Laccaria spp. were type I. Most of the isolates $(80+\%)$ were type II. Only 7 isolates were type III, including $C$. geophilum and $H$. crustuliniforme (Coleman et al., 1988). These results indicate that fungi do differ in their abilities to grow under imposed water stress in pure culture. We have synthesized mycorrhizal seedlings with some of these isolates and are studying their effects on the water relations of Douglas fir seedlings (Coleman, personal communication).

Fig. 4. Rhizopogon mycorrhizae: autoradiogram of rDNA EcoRl blot-hybridization pattern (Rogers et al., 1988). 


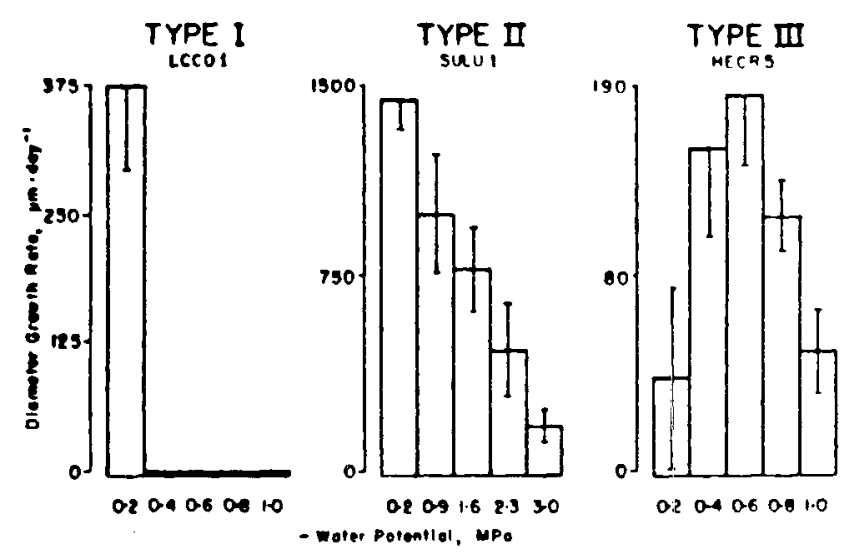

Fig. 5. Diameter growth rate ( $\mu \mathrm{m} /$ day) of fungi grown under imposed water stress, $-0.2+-3.0 \mathrm{MPa}$ (Coleman et al., 1988).

\section{Summary and Conclusions}

In addition to our work, other papers presented at this symposium report on mycorrhizal physiology. For example, the soils work in Germany by Ritter and coworkers shows effects of liming soils on species diversity of fungi. In nutritional studies, Rousseau and Reid from Florida, USA, have focused on phosphorus uptake and translocation, while Vezina et al., from Laval, Quebec, evaluated metabolism of nitrogen supplied in different forms. More detailed metabolic studies at the University of Nancy by Chalot and coworkers showed more efficient uptake of ammonium by mycorrhizal plants. Not only nutrients but also carbon biochemistry is affected by mycorrhizae as reported by Namysl et al., also at the University of Nancy. Several papers discussed interactions in the rhizosphere, such as ElBadaqui et al.'s report on mycorrhizal production of extracellular phosphatases. Succession of different mycorrhizal types on seedlings and young trees was report- ed by Blasius et al. These research results illustrate the intense interest in understanding how mycorrhizae affect host nutrition and physiology.

With the use of new techniques and methods, we are now able to understand not only how fungi affect nutrient uptake and tree nutrition but also to study more specific effects of individual fungal species. In the future, we expect that we will understand fungal physiological diversity sufficiently to be able to select certain fungal partners for specific field and environmental conditions. New areas of research will probably include: host-fungus recognition, genetic engineering of mycorrhizal fungi, studies of spatial patterns of mycorrhizal roots in forest soils and microbial interactions in the rhizosphere.

\section{Acknowledgments}

We appreciate the technical assistance provided by Suzanne Bagshaw, Faridah Dahlan, Kelly Leslie, Kim Do and Kathy Parker. 


\section{References}

Bledsoe C.S. (1987) Ecophysiological diversity of ectomycorrhizae. In: Current Topics in Forest Research, U.S. Forest Service S.E. Exp. Stn. Tech. Report No. SE-46, pp. 14-19

Bledsoe C. \& Rygiewicz P.T. (1986) Ectomycorrhizae affect ionic balance during ammonium uptake by Douglas fir roots. New Phytol. 102, 271-283

Cole D.W. \& Bledsoe C.S. (1976) Nutrient dynamic of Douglas fir. IVI IUFRO World Congress Proceedings, Div. II, pp. 53-64

Coleman M.D., Bledsoe C.S. \& Lopushinsky W. (1989) Pure culture response of ectomyc. fungi to imposed water stress. Can. J. Bot. 67, 29-39

Littke W.R., Bledsoe C.S. \& Edmonds R.L. (1984) Nitrogen uptake \& growth in vitro by
Hebeloma crustuliniforme and other Pacific NW mycorrhizal fungi. Can. J. Bot. 62, 647-652

Rogers S.O., Rehner S., Bledsoe C., Mueller G.J. \& Ammirati J.F. (1989) Extraction of DNA from fresh, dried \& lyophilized fungus tissue for ribosomal DNA hybridizations. Can. J. Bot. 67 , 1235-1243

Rygiewicz P.T. \& Bledsoe C.S. (1984) Mycorrhizal effects on potassium fluxes by Northwest coniferous seedlings. Plant Physiol. 76, 918923

Rygiewicz P.T., Bledsoe C.S. \& Zasoski R.J. (1984a) Effects of ectomycorrhizae \& solution $\mathrm{pH}$ on $15 \mathrm{~N}$ ammonium uptake by coniferous seedlings. Can. J. For. Res. 14, 885-892

Rygiewicz P.T., Bledsoe C.S. \& Zasoski R.J. (1984b) Effects of ectomycorrhizae and solution $\mathrm{pH}$ on $15 \mathrm{~N}$ nitrate uptake by coniferous seedlings. Can. J. For. Res. 14, 893-899 